\title{
Effect of maternal hyperalimentation on intrauterine growth retardation
}

\author{
F DE PRINS, ${ }^{*}$ D J HILL, $\dagger$ R D G MILNER, $\dagger$ AND A VAN ASSCHE* \\ *Unit for the Study of Reproduction, Department of Developmental Biology, Catholic University of Leuven, \\ Belgium and +Department of Paediatrics, University of Sheffield, England
}

SUMMARY The effect of maternal hyperalimentation on intrauterine growth retardation was studied by performing unilateral uterine vessel ligation on day 17 in Wistar rats. Test animals were given food supplements by gavage for three days postoperatively whereas control animals received saline. The caloric intake and weight gain of the test dams was significantly greater than that of the controls from days 17 to 20 but not over the longer period, day 14 to 23 . The survival and growth of fetuses in the unoperated horn were similar in test and control rats. Fetal survival in the ligated horn was doubled by maternal food supplementation but the growth and development of the survivors were not improved.

Intrauterine growth retardation (IUGR) has many causes and in human pregnancy maternal vasculopathy is responsible for roughly one third of all cases. ${ }^{1}$ Starvation during pregnancy also leads to IUGR and in undernourished populations caloric supplementation during pregnancy can cause a modest increase of birth weight. ${ }^{2}$ There is a limited therapeutic repertoire available to the clinician who has to deal with $\mathrm{IUGR}^{3}$ and we were therefore interested to see if maternal food supplementation could benefit fetal outcome in pregnancies with IUGR due to vascular disease. The Wigglesworth model of intrauterine growth retardation in the rat is an appropriate example of uterine vasculopathy and this study examined the effect of maternal food supplementation on fetal outcome in this model. ${ }^{4}$

\section{Materials and methods}

\section{ANIMALS}

Primiparous Wistar rats, 80 to 120 days old from the University of Nottingham animal house, were used. First, in order to test if the completely absorbable diet would sustain pregnancy as well as a conventional diet pregnancy outcome was compared between four animals that were fed a conventional laboratory diet (RMH-GS, Hope Farms, The Netherlands) during their whole gestation and four animals that were switched to a completely absorbable powder diet (Precitene-N, Sanofi, Belgium) from day 14 of pregnancy. Percentage weight increase per 24 hours and caloric uptake in $\mathrm{kcal} / \mathrm{kg} /$ 24 hours were recorded from day 14 by direct weighing. At day 22 the dams were sectioned under pentobarbitone anaesthesia. Litter size and fetal survival rate were compared between control and test groups. Mean values for daily caloric uptake, daily weight gain, fetal body weight, and placental weight were calculated per dam.

Then 17 primigravid English Wistar rats with known duration of pregnancy were given Precitene$\mathrm{N}$ from day 14 . At day 17 the uterine vessels were ligated unilaterally. ${ }^{4}$ Ten dams received food supplements from day 17 to 19 inclusive. Supplements were given as concentrated solutions of $20 \mathrm{~g}$ Precitene- $\mathrm{N}$ in $12 \mathrm{ml}$ water. According to the technique described by Waynforth, the solution was administered by the intragastric route using a 15 gauge needle with a bulbous tip on a $10 \mathrm{ml}$ syringe. ${ }^{5}$ The rats were held firmly by the skin of the neck so that the head was immobile and the mouth opened. The needle, attached to the syringe, was then passed into the stomach. One to two $\mathrm{ml}$ of the Precitene-N solution were given at a time and maximum daily amounts were $16 \mathrm{ml}$. Equal amounts of physiologic saline were given in the same way to seven control rats. Meanwhile test and control dams always had free access to Precitene-N powder and water. Maternal body weight and total food uptake were recorded daily. The Wilcoxon matched pairs signed ranks test was used to evaluate the difference between food supplemented and sham treated dams. 
At day 23 the dams were anaesthetised with intraperitoneal nembutal and delivered operatively. Fetal blood was sampled from the axillary vessels while the placental circulation was still intact. ${ }^{6}$ Blood was pooled from all fetuses within a single uterine horn and stored at $-20^{\circ} \mathrm{C}$ until analysed. Fetuses and placentas were then weighed to accuracies of $0.1 \mathrm{~g}$ and $1 \mathrm{mg}$, respectively. From each fetus liver and pancreas were removed in toto, weighed, and kept for further analysis. Fetal livers were stored at $-20^{\circ} \mathrm{C}$ until analysed.

\section{LABORATORY METHODS}

Plasma somatomedin like activity was measured by bioassay in which ${ }^{35} \mathrm{~S}$ sulphate uptake by fetal rat costal cartilage was the test system and the reference standard was a pool of adult rat plasma $(5 \% \mathrm{v} / \mathrm{v}){ }^{7}$

Each fetal liver was homogenised in deionised water in a Potter-Elvehjeim homogeniser. Hepatic protein concentration was determined using bovine serum albumin as a standard. ${ }^{8}$ Deoxyribonucleic acid (DNA) was measured using calf thymus DNA (Sigma Chemical, Dorset) as a standard." Aliquots of liver homogenate were extracted twice with $0.5 \mathrm{~N}$ perchloric acid for 30 minutes at $80^{\circ} \mathrm{C}$ with a yield of $95 \%$. As suggested, acetaldehyde solution $(2.05 \%)$ was added to the diphenylamine reagent immediately before use. ${ }^{11}$

Fetal pancreas was fixed in Bouin's solution and embedded in paraffin wax. Tissue sections were stained immunocytochemically for insulin and pancreatic polypeptide by the unlabelled antibody enzyme method. ${ }^{11}$ Two sections from each tissue block were used for the morphometric determination of pancreatic $\mathrm{B}$ cell density. ${ }^{12}$ The number of points counted per pancreas was 51200 resulting in standard errors of $4 \%$ per fetus and 0.6 to $2.0 \%$ for a group of fetuses within a litter. ${ }^{13}$ From the pancreatic B cell volume density, pancreatic weight, and body weight, the relative weight of B cells in the fetus was calculated.

STATISTICAL ANALYSES

Differences in maternal responses to the two diets were compared by Student's $t$ test. Parameters of fetal outcome such as survival or plasma somatomedin like activity were averaged per uterine horn. The Mann-Whitney test was used to compare these parameters between ligated and non-ligated horns in food supplemented and sham treated dams. Fetal body weight and organ characteristics should have been subjected to analysis of variance with hierarchial classification ${ }^{14}$ but this was not possible because of the high fetal death rate in the ligated horn of the sham supplemented dams.

\section{Results}

The chemical composition of the conventional laboratory diet and the completely absorbable powder diet differed ${ }^{15}$ but were similar and each fulfilled the estimated requirements for adequate rat nutrition. ${ }^{16}$ Pregnant rats fed the absorbable powder diet from day 14 to 22 took on average (SEM) 197 (9) $\mathrm{kcal} / \mathrm{kg} / 24$ hours $(0.82(0.04) \mathrm{MJ})$ which was significantly less than that of those fed conventionally: $273(9)(1 \cdot 14(0 \cdot 04) \mathrm{MJ})(\mathrm{p}<0 \cdot 005)$. Despite this the mean (SEM) weight gain of the two quartets was similar: $2.7(0 \cdot 1) \%$ increase/day, as were the litter size (13 (2) $v 13$ (1)), fetal survival rate $(100 \% v 98 \%)$, fetal body weight $(4 \cdot 4(0 \cdot 1)$ g each), and placental weight $(453(25) v 443(25) \mathrm{mg})$. It was concluded that the pregnant rats thrived equally on either diet.

In the definitive experiment where dietary intake was supplemented by gavage after unilateral uterine vessel ligation on day 17 of pregnancy, the food supplemented dams both received more calories and gained more weight from days 17 to 20 , but when similar analyses were performed over the period 14 to 23 days no significant difference between the groups could be detected (table 1). Dietary intake in the first three postoperative days was significantly down in both groups, more so in the sham treated.

Comparisons of the effects of uterine vessel ligation and maternal food supplementation are presented in table 2. Considering first the control horns: there was no significant difference between the food supplemented and sham supplemented groups in any parameter studied. The effect of

Table 1 Mean (SE) maternal nutrition and weight gain after uterine vessel ligation on day 17 of food supplemented or sham treated pregnant rats

\begin{tabular}{|c|c|c|c|c|}
\hline \multirow[t]{2}{*}{ Treatment } & \multicolumn{2}{|c|}{ Caloric uptake (kcal/kg/24 hours) } & \multicolumn{2}{|c|}{ Daily weight gain ( $\%$ increase 24 hours) } \\
\hline & Day 14 to 23 & Day 17 to 20 & Day 14 to 23 & Day 17 to 20 \\
\hline Food supplemented rats $(n=10)$ & $197(7)$ & $160(10)^{*}$ & $+1 \cdot 3(0 \cdot 2)$ & $+1 \cdot 2(0 \cdot 3)^{*}$ \\
\hline Sham treated rats $(n=7)$ & $184(9)$ & $127(10)$ & $+(0 \cdot 9)(0 \cdot 1)$ & $-0.2(0 \cdot 2)$ \\
\hline
\end{tabular}

Significance of difference of food supplemented $v$ sham treated: * $\mathrm{p}<0.015$. 
Table 2 Mean (SE) fetal outcome on day 23 after unilateral uterine vesel ligation on day 17 of pregnant rats subsequently given food supplements or sham supplements

\begin{tabular}{|c|c|c|c|c|c|c|c|}
\hline \multirow[b]{3}{*}{ No survivors/dam } & \multicolumn{3}{|c|}{ Sham supplement } & \multicolumn{4}{|c|}{ Food supplement } \\
\hline & Ligated horn & \multicolumn{2}{|c|}{ Control horn } & \multicolumn{2}{|c|}{ Ligated horn } & \multicolumn{2}{|c|}{ Control horn } \\
\hline & $0 \cdot 6(0 \cdot 3)$ & $4.9(0.5)$ & [7] & $2 \cdot 0(0 \cdot 5)$ & {$[10]$} & $4 \cdot 4(0 \cdot 5)$ & [10] \\
\hline Survival rate $(\%)$ & $13(7)$ & $97(3)$ & [7] & $40(9)$ & {$[10]$} & $83(4)$ & {$[10]$} \\
\hline Body weight (g) & $4 \cdot 5(0 \cdot 5)$ & $5 \cdot 3(0 \cdot 1)$ & [34] & $4 \cdot 5(0 \cdot 2)$ & {$[20]^{* *}$} & $5 \cdot 6(0 \cdot 1)$ & [10] \\
\hline Placental weight (mg) & 459 (47) & 498 (14) & [34] & $452(26)$ & {$[20]^{* *}$} & $529(16)$ & [44] \\
\hline Pancreas weight (mg) & $22(2)$ & 27 (1) & [34] & 23 (1) & {$[20]^{* *}$} & $28(1)$ & [44] \\
\hline Liver weight (mg) & $255(40)$ & $345(12)$ & [34] & $233(15)$ & {$[20]^{* *}$} & $346(9)$ & [44] \\
\hline Liver DNA $(\mu \mathrm{g})$ & $154(17)$ & $173(10)$ & [34] & $136(10)$ & {$[20]^{* *}$} & $189(9)$ & [44] \\
\hline Liver protein/DNA & 317 & $364(10)$ & {$[34]$} & $322(20)$ & {$[20]$} & 327 (14) & [44] \\
\hline Plasma somatomedin like activity $(\mathrm{U} / \mathrm{ml})$ & $0.98(0 \cdot 17)[3]$ & $1 \cdot 35(0 \cdot 24$ & [5] & $1.06(0 \cdot 13$ & {$[8]^{* *}$} & $2 \cdot 18(0 \cdot 44$ & ) $[8]$ \\
\hline
\end{tabular}

The number of observations is shown in square brackets.

Significance of difference for fetuses in the ligated horns of fed $v$ sham supplemented mothers: ${ }^{*} \mathrm{p}<0 \cdot 05$, and for fetuses in the ligated $v$ control horns of the same supplement group: ${ }^{* *} \mathrm{p}<0 \cdot 05$.

uterine vessels ligation in the food supplemented group was to halve the number of survivors per horn and cause a small but significant reduction in their body weight, a significant reduction in plasma somatomedin like activity, placenta, pancreas, and liver weights but no significant change in the hepatic protein:DNA ratio. In the food supplemented group the mean (SEM) pancreatic $B$ cell volume density of the survivors in the ligated horn was similar to that in the control horn $(1.12(0.09)$ and $1.41(0 \cdot 14) \%$, respectively) as was the fractional contribution of B cell weight to body weight (59 (4) and $69(6) \mu \mathrm{g} / \mathrm{g}$, respectively).

In stark contrast, ligation in the sham supplemented group resulted in the death of all or all but one of the fetuses in the uterine horn. Four fetuses survived in seven ligated uterine horns. The body, organ, and biochemical characteristics of these four fetuses had the same relation to the fetuses in the control horn as had been noted between the fetuses in the ligated and control horns of the food supplemented group.

It was concluded that food supplementation protected against the fetal mortality associated with uterine vessel ligation but had no effect on the morbidity.

\section{Discussion}

These experiments were designed to study the effect of maternal food supplementation on fetal outcome in the presence of restricted uteroplacental circulation. The rat was chosen as the experimental model because of the large experience with uterine vessel ligation in this species but it was hoped that the results might have more general biological implications.

Nutritional supplementation can be given en- terally or parenterally. Pilot experiments showed that the combination of laparotomy for uterine vessel ligation with constant intravenous infusion led to an unacceptably high maternal mortality, hence gavage was chosen to supplement maternal intake. The completely absorbable diet Precitene- $\mathrm{N}$ was used because it can be dissolved for gavage feeding as well as being eaten by rats in powder form. Although Precitene-N differs in detail from commercial rat chow, there are many similarities and it contains all the recommended nutrients for the rat. The preliminary experiment established that both mother and fetus fared equally well on either diet. Gavage was a satisfactory technique for food supplementation because the rat has a poorly developed vomiting reflex. ${ }^{17}$ Under nembutal anaesthesia up to $6 \mathrm{ml}$ Precitene- $\mathrm{N}$ could be given and supplementation of conscious rats with $1-2 \mathrm{ml}$ at a time was easy. In general the rat eats according to its energy requirement and forced feeding is accompanied by reduced spontaneous food intake. In the present experiments food supplementation was important from day 17 to 20 when spontaneous food intake was low in the immediate postoperative period. At this time the food supplemented rats ingested roughly $30 \%$ more than the sham treated controls and they continued to gain weight, whereas over the whole study period of 14 to 23 days there was no significant difference in energy intake or weight gain of food supplemented or sham supplemented animals.

The experiments were designed to permit analysis of the effects of maternal food supplementation and uterine vessel ligation separately and together. Gavage by itself had no effect, adverse or beneficial, on fetal outcome. Uterine vessel ligation produced a high fetal mortality with only one fetus maximum surviving in the experimental horn and three out of 
seven dams losing all the fetuses in the ligated horn. This result was clearly related to the colony of animals because the same investigator (F De P) had earlier performed identical operations on an English colony of Wistar rats with an average $54 \%$ fetal survival and $92 \%$ of the mothers having one or more living fetuses. The growth and composition of the four surviving fetuses was similar to that of the fetuses in the ligated horn of the food supplemented group; the difference between the two being in the number of survivors, on average two fetuses out of four survived in the food supplemented group and no food supplemented dam failed to have at least one survivor in the ligated horn. Thus food supplementation improved survival of fetuses experiencing uterine vascular impairment but had no effect on the size of the survivor. It remains a matter of speculation as to what effect food supplementation might have had on a colony in which spontaneous survival in a ligated horn was higher.

Analyses of fetal body and organ weight and composition gave similar results between the control and test animals for ligated and non-ligated horns, respectively. Fetal growth was most advanced in the non-ligated horns of the food supplemented rats where the fetuses were the most favoured by the experimental design. They also had the highest plasma somatomedin like activity, total liver DNA, and relative weight of $\mathrm{B}$ cells. These findings are compatible with the idea that the relative weight of $B$ cells reflects the growth capacity of the fetus and they confirm the positive correlation between body weight and plasma somatomedin like activity described earlier ${ }^{18}$ Liver weight was strikingly lower in the test fetuses of both food supplemented and non-supplemented mothers confirming the findings of others. ${ }^{19}$ The extent of the liver weight reduction, roughly $25 \%$, was too great to be explained by glycogen alone. Analyses of protein and DNA showed preservation of the protein:DNA ratio in all subgroups of fetuses and the reduction of hepatic weight was therefore due to fewer, not smaller, cells. The similarity of placental weight in the subgroups indicates that maternal hyperalimentation does not influence fetal outcome by stimulating placental growth.

Extrapolation of these results to any other species would be inappropriate apart from the general and clear cut observation that fetal outcome can be importantly affected by the plane of maternal nutrition, particularly in a postoperative period late in gestation.

We thank Ms Rieta Van Bree for skilful technical help and Andre Bocl, Informatie-verweking, University of Leuven for help with statistical analyses.

\section{References}

1 The causes of small-for-dates birth. General discussion. In: Elliot K, Knight J, eds. Size at birth. Amsterdam: Associated Scientific Publishers, 1974:383-97.

? Habicht JP. Yarbrough C. Lechtig A. Klein RE. Relation of maternal supplementary feeding during pregnancy to birth weight and other sociobiological factors. In: Winick M. ed. Nutrition and fetal development. New York: Wilcy, 1974: 127-45.

3 Nicolaides KH. Campbell S. Bradley RJ, Bilardo CM. Soothill PW, Gibb D. Maternal oxygen therapy for intrauterine growth retardation. Lancet 1987;i:942-5.

+ Wigglesworth JS. Experimental growth retardation in the fetal rat. Journal of Pathology and Bacteriology 1964;88:1-13.

Waynforth HB. Injection techniques. In: Waynforth HB, ed. Experimental and surgical techniques in the rat. London: Academic Press, 1980.

6 Kervran A. Gilbert M. Girard JR, Jost A. Effect of environmental temperature on glucose-induced insulin response in the newborn rat. Diabetes 1976;25:1026-30.

7 Hill DJ. Andrews SJ, Milner RDG. Cartilage response to plasma and somatomedin activity in rats related to growth before and after birth. J Endocrinol 1983;90:133-42.

' Lowry OH, Roscbrough NJ, Farr AL. Randall RJ. Protein measurement with Folin phenol reagent. J Biol Chem 1951:193: $165-75$.

"Burton K. A study of the conditions and mechanisms of the diphenylamine reaction for the colorimetric estimation of deoxyribonucleic acid. Biochem $J$ 1956:62:315-23.

11 Giles KW, Myers A. An improved diphenylamine method for the estimation of deoxyribonucleic acid. Nature 1965;206:93.

$"$ Sternberger LA. Handy PH, Curculis JJ. Meyer HC. An unlabeled antibody method of immunochemistry. $J$ Histochem Cytochem 1976:18:315-40.

12 De Prins FA, Van Assche FA. Intrauterine growth retardation and development of endocrine pancreas in the experimental rat. Biol Neonate 1982;41:16-21.

1.3 Weibel ER. Point counting methods. In: Weibel ER, ed. Stereological methods. Vol 1. London: Academic Press, 1979:101-61.

14 Li CC. Hierarchical classifications. In: Li CC, ed. Introduction to experimental statistics. New York: McGraw-Hill Book Company, 1964:75-83.

15 De Prins F. Fetal consequences of growth retardation on a vascular basis. A study in an animal model. Leuven: University of Leuven, 1987. (PhD thesis)

16 Committec on animal nutrition. National requirements of the laboratory rat. National Academy of Sciences, Nutrient requirements of laboratory animals. Washington DC: Office of Publications, 1978:7-37.

17 Briggs GB, Dehme FW. Toxicology. In: Baker HJ. Lindsey JR. Weisbroth SH, eds. The laboratory rat. Vol II. Research applications. New York: Academic Press, 1980:103-18.

16 De Prins FA, Hill DJ. Fekete M. Robson D. Van Assche FA. Milner RDG. Reduced plasma somatomedin activity and sulphate incorporation by costal cartilage in vitro during experimental growth retardation in the fetal rat. Pediatr Res 1984:18:1100-4.

19 Roux JM, Tordet-Caridroit C. Chanez C. Studies on experimental hypotrophy in the rat. I. Chemical composition of the total body and some organs in the rat foetus. Biol Neonate 1976:29:262-6.

Correspondence to Professor RDG Milner, Department of Paediatrics, Children's Hospital, Sheffield S10 2TH.

Accepted 11 November 1987 